\title{
Green Market Segmentation: A Case of Airline Customers in Taiwan
}

\author{
Fang-Yuan Chen ${ }^{1}$, Shih-Liang $\mathrm{Tu}^{2} \&$ Hsin-Erh Wang ${ }^{1}$ \\ ${ }^{1}$ Department of Transportation Technology and Management, Feng Chia University, Taichung, Taiwan \\ ${ }^{2}$ The World Bank Consultant, Senior Environment Specialist of Asian Development Bank \\ Correspondence: Fang-Yuan Chen, Department of Transportation Technology and Management, Feng Chia \\ University, Taichung, Taiwan. E-mail: fychen@fcu.edu.tw
}

Received: October 7, 2015 Accepted: October 22, 2015 Online Published: January 26, 2016

doi:10.5539/jsd.v9n1p99 URL: http://dx.doi.org/10.5539/jsd.v9n1p99

\begin{abstract}
Green marketing has evolved in line with an increase in consumers' concern with the environment. This study explores whether an environmentally-oriented market niche exists within the airline transport market in Taiwan. Based on a survey of 416 airline customers, this study uses factor analysis and cluster analysis to segment customers based on their environmental behaviors. Three distinct clusters were identified (i.e., the environmentally indifferent, the enlightened environmentalists, and the active environmentalists) and further profiled with respect to the socio-demographic, behavioral, and attitudinal characteristics. The results suggest that the segment of green consumers is large enough to warrant airline marketers' attention and the enlightened and the active environmentalists appear to represent the most promising target markets. The practical implications of the findings and future research directions are discussed.
\end{abstract}

Keywords: green marketing, market segmentation, environmental behavior, environmental knowledge, environmental attitude, pro-environmental air travel intention

\section{Introduction}

The environmental impacts of the airline industry is of increasing importance to the general public. According to an International Air Transport Association (IATA) report, the aviation industry is responsible for $2-3 \%$ of global anthropogenic $\mathrm{CO} 2$ emissions, approximately $12 \%$ of the global transport industry's emission of $\mathrm{CO} 2$ (IATA, 2012; Clarke, 2006). Consequently, the airline industry has implemented various supply-side measures, such as fleet modernization, improved air traffic control, and initiatives on the ground, to reduce the negative impacts on the environment. (Li et al., 2003; El-Mobaidh et al., 2006; Hares et ak., 2010).

However, airlines have devoted substantially less effort to understanding their customers' perspectives on environmental issues and how these views affect their behavior (Lassen, 2010). Previous research has demonstrated that environmental problems industry-wise cannot be solved with technical or economic measures alone and that an enhanced understanding of consumers' attitude and buying behavior is critical to airlines' environmental planning (Tikka et al., 2000; Abdul-Wahab, 2008).

Given that consumers are becoming more environmentally conscious and seek to purchase eco-friendlier products and services, firms have realized the need to incorporate these new concerns in their business strategies (Lynes \& Dredge, 2006). As a result, green marketing now has a higher priority on corporate agenda for numerous industries (Siriwardena et al., 2012). To target the growing green segment, firms must understand how substantial the green segment is and who these environmentally conscious customers are, including their characteristics and preferences (Ginsberg \& Bloom, 2004; Siriwardena et al., 2012). To this end, green market segmentation can be used to identify, anticipate, and satisfy the needs of the environmentally aware consumers (Mostafa, 2006; Rivera-Camino, 2007; Thompson et al., 2010). Researchers have also called for further development of green market segmentation to better understand consumer profiles that can be used to guide environmental strategy formulation (Jain \& Kaur, 2006; Paço \& Raposo, 2009).

Taiwanese airlines have lagged behind other sectors (in particular, the manufacturing industries) in recognizing and addressing environmental concerns. Only recently have Taiwanese airlines begun to systematically promote environmental management at the corporate level. Although significant efforts have been made in sustainability issues such as fuel and water conservation, there is scant knowledge on the size and characteristics of the green 
marketplace in Taiwan's airline industry. With increasing consumers awareness, an enhanced understanding of consumer profiles and their characteristics has become critical to Taiwanese airlines' environmental planning.

This study strives to make two specific contributions to the environmental literature. First, although studies on green segmentation have been conducted in various contexts in North America and Europe (Straughan \& Roberts, 1999; Vicente \& Reis, 2007; Paço \& Raposo, 2009, 2010; Thompson et al., 2010), few has explored the consumer profiling in the air transport sector of a non-Western economy. This research intends to fill that knowledge gap. Factor and cluster analyses were employed in this study to explore whether an environmentally-oriented market niche exists in the air transport industry in Taiwan.

Second, this study profiles the airline industry's consumers based on their environmental behaviors. Such behaviors were used because they represent discernible activities of individuals that protect the environment. Demographic and other environmental criteria are investigated across the segments. The findings of this study, therefore, may provide airline marketers with a better understanding of the consumers' profile and likewise offer guidelines for green marketing activities to reach these environmentally aware customers.

\section{Conceptual Background}

\subsection{Green Market Segmentation}

Green marketing is concerned with the design, development, and delivery of products that are eco-friendly and inflict minimal harm to the environment and the stakeholders of a firm (Chitra, 2007). Market segmentation is an integral first step in the formulation of a successful marketing strategy. Green market segmentation refers to the process of classifying consumers into segments based on their levels of environmental awareness, concerns for, and emotional attachment to the environment. Consumers in each segment may exhibit different degrees (or a lack) of environmentally friendly behavior that may require separate products or marketing mixes (Paço \& Raposo, 2009, 2010). Green segmentation enables firms to better understand people who care for the environment and design suitable targeting and positioning strategies to attract them (Paço \& Raposo, 2009; Laroche et al., 2001; Straughan \& Roberts, 1999).

The market segmentation process starts with the selection of a set of variables or characteristics that are used as segmentation bases to assign consumers to homogeneous groups.

Previous studies on green marketing have attempted to segment the green consumer market using socio-demographic, psychographic, behavioral, and environmental criteria. For example, the Natural Marketing Institute has developed a segmentation model for the U.S. adult consumers based on attitudinal and lifestyle variables and identified five distinct consumer groups: LOHAS (Lifestyles Of Health And Sustainability), Naturalites, Drifters, Conventionals, and Unconcerneds (Ottman, 2011). Among these five segments, LOHAS represents consumers who have strong attitudes regarding personal and planetary health that are widely reflected in their behavior. They are driven to protect the environment and avid users of green products. Straughan \& Roberts (1999) provided a method for segmenting and profiling college students based on their ecologically conscious consumer behavior and found that demographic variables were not as useful a profiling method as psychographic variables. In their model, the psychographic variables that are useful included altruism, liberalism, environmental concern, and perceived consumer effectiveness. Laroche et al. (2001) used demographic, psychographic, and behavioral profiles to identify consumers who were likely to pay more for environmentally friendly products. Their sample was divided into "willing", "unwilling" and "undecided" groups based on their responses to survey questions. Kerstetter et al. (2004) developed a motivational and behavioral profile for a distinct segment of ecotourists in Taiwan. They found that tourists' motivations for visiting coastal wetlands vary and identified three types of tourists based on their environmentally responsible behaviors. Paço \& Raposo (2010) used demographic and environmental criteria to identify distinct market segments in the Portuguese consumer market. Environmental criteria included environmental knowledge and concern, environmental affect, environmentally friendly behaviors, price sensitivity, environmental skepticism, and activism. In the air transport context, Lassen (2010) used in-depth interviews to explore the connection between air travel and environmental attitudes among knowledge workers in Denmark and identified two groups of travelers: deniers and bystanders. The deniers do not think air travel is related to climate change problems, whereas bystanders acknowledge it, but they have excluded the issue from their general environmental attitude and it does not affect their actual travel behavior.

These mentioned studies suggest that a crucial task for green marketing is defining the characteristics and preference for segmentation purposes, which can be used to design suitable targeting and positioning strategies. In addition, the review indicates that the bases of segmentation appear to be similar. Although demographic variables were analyzed in most of these studies, these variables provided limited help in identification of green 
consumers. Traditional socio-demographic variables are often complemented by other types of information (e.g., psychographic or attitudinal variables) to obtain a more comprehensive understanding of green consumers.

\subsection{Socio-Demographic Characteristics}

Gender, age, income, education, and occupation are among the primary demographic variables that have been used as bases for segmenting and profiling green consumers in previous studies (Jain \& Kaur, 2006; Diamantopoulos et al., 2003; Straughan \& Roberts, 1999; Shen \& Saijo, 2008).

The majority of these studies have found that males are environmentally more knowledgeable than females (Arcury et al., 1987; Zelezny et al., 2000), although others have reported no significant relationship between gender and environmental knowledge (Diamantopoulos et al., 2003). On the other hand, females are reportedly more ecologically conscious and engage in more eco-conscious behaviors than males as a result of social development and gender role differences (Straughan \& Roberts, 1999; Lee, 2008; Diamantopoulos et al., 2003; Shrum et al., 1995).

The relationship between age and environmental consciousness has proven more consistent. The majority of previous studies report a significant and negative relationship between age and environmental knowledge, attitudes, and behavior (Arcury et al., 1987; Diamantopoulos et al., 2003). The studies by Lee (2008) and Howell $\&$ Laska (1992) have shown that younger people are more concerned with the deterioration of the environmental. However, Roberts (1996) found that older consumers tend to engage in more ecologically conscious behaviors.

Similar to age, the relationship between level of education and environmental consciousness is relatively consistent. Most studies show education is positively correlated to environmental knowledge, attitudes, and behaviors (Diamantopoulos et al., 2003; Roberts, 1996). A few studies, however, have found that education is not a good predictor of environmental concern or purchasing behaviors (Roberts, 1996; Samdahl \& Robertson, 1989).

Most studies concur in that income level is generally positively related to ecologically conscious behaviors, based on the belief that people with higher income levels can more easily afford the higher costs associated with green products and supporting green causes (Straughan \& Roberts, 1999; Chan, 1999). There are, however, a few studies that report an insignificant or even a negative relationship between income and environmental knowledge, attitudes, and behavior (Van Liere \& Dunlap, 1981; Roberts, 1996; Samdahl \& Robertson, 1989).

Previous studies regarding the influence of occupation on environmental consciousness have yielded inconsistent results. While some studies report a significant relationship between occupation and environmental attitudes (Balderjahn, 1988), no such relationship could be found in other research (Van Liere \& Dunlap, 1981; Samdahl \& Robertson, 1989).

Despite the inconsistencies in past research concerning the influence of consumers' demographics on their environmental consciousness, marketers often use demographic characteristics as segmentation criteria because they are easy to assess and that they have the secondary benefit of assisting in the planning of targeted communication efforts (Diamantopoulos et al., 2003; Roberts, 1996). Nevertheless, most studies agree that demographics are less satisfactory than environmental criteria in predicting consumers' environmental behaviors (Laroche et al., 2001; Chan, 1999; Straughan \& Roberts, 1999).

\subsection{Environmental Criteria}

\subsubsection{Environmental Knowledge}

Environmental knowledge refers to "a general knowledge of facts, concepts, and relationships concerning the natural environment and its major ecosystem" (Fryxell \& Lo, 2003). Various measures have been used to assess consumers' environmental knowledge. Factual knowledge assesses consumers' actual understanding of environmental issues: problems, causes, and solutions. Action-related knowledge relates to behavioral knowledge and patterns that can be utilized and acted upon (Polonsky et al., 2011). Empirical research on the influence of consumers' environmental knowledge on their environmental behavior is contradictory. Although some studies have shown that environmental knowledge is a significant factor in predicting environmentally friendly behaviors (Chan, 1999), other studies have shown no substantial link between these two variables (Laroche et al., 2001; Hines et al., 1987).

\subsubsection{Environmental Attitude}

Environmental attitude refers to "individuals' level of concern or interest about specific or general aspects of environmental, ecological or energy-saving phenomena" in environmental studies (Schlegelmilch et al., 1996). It reflects an individual's perspective regarding humans' relationship with the nature. Although the usual findings 
suggest a positive association between environmental attitude and environmentally friendly behavior (Stern, 2000; Mostafa, 2006), some studies have found either a moderate or a weak relationship between these two variables (Lee, 2008; Mostafa, 2006; Lassen, 2010), meaning that a positive environmental attitude does not necessarily result in action. This attitude-behavior gap suggests that other possible variables may also predict environmental behavior (Robert, 1996). The most notable scale for measuring environmental attitudes is the New Environmental Paradigm (NEP) scale developed by Dunlap \& Van Liere (1978) and later revised as the New Ecological Paradigm scale. This scale was developed to evaluate the degree of an individual's environmental orientation, which represents an eco-centric worldview that recognizes the balance of nature, limits of growth, and human over nature.

\subsubsection{Environmental Behavior}

Environmental behavior refers to behaviors that consciously seek to minimize the negative impact of one's actions on the natural environment (Kollmuss \& Agyeman, 2002). Roberts (1996) pointed out that the investigation of consumers' environmental behavior is crucial because these behaviors, rather than expressed concerns, that protect the environment. Stern (2000) suggested that environmental behavior can be defined from an impact-oriented or an intent-oriented perspective. The impact-oriented perspective refers to the actual behavior that helps reduce the negative impact of human behavior on the environment. The intent-oriented perspective, however, focuses on the investigation of people's beliefs and motives to understand and change their behaviors with the intention to benefit the environment. In particular, the personal, private-sphere behaviors that occur in daily-life settings (e.g., recycling, household waste disposal, energy saving) could have direct impact on the environment (Stern, 2000).

\subsubsection{Environmental Affect}

Environmental affect refers to the emotion that an individual expresses in relation to environmental issues (Paço \& Raposo, 2010). Previous research has established a positive association between environmental affect and ecological behavior (Chan \& Yam, 1995; Chau \& Lau, 2000). It is worthy to note that people with a low level of environmental knowledge may still exhibit a high emotional attachment to the environment (Chan, 1999). In their study, Chan \& Yam (1995) concluded that ecological affect and ecological knowledge are two distinct variables affecting environmental behavior. Steg \& Vlek (2009) also considered affect a significant factor in motivating people to engage in environmental behavior.

\subsubsection{Environmental Responsibility}

In environmental psychology literature, some researchers have explained ecological behavior from a social or an altruistic perspective (Kaiser et al., 1999). Hines et al. (1987) proposed a model of responsible environmental behavior in which personal responsibility, which represents an individual's feelings of obligation toward the environment, is a critical personality factor in influencing one's intention to perform environmentally friendly actions. It is logical that people who assume personal responsibility for protecting the environment are more likely to make sacrifices for an improved ecosystem. Stern (2000) also argued that people's sense of responsibility toward the environment guides their environmental behavior. Lee (2008) found that perceived environmental responsibility was the second most important factor in predicting female adolescents' environmental behavior in Hong Kong.

\subsubsection{Environmental Skepticism}

As an increasing number of green products are introduced to the marketplace, more companies are making environmental claims to market their products. However, recent research has observed a gap between actual consumer purchasing of green products and verbally expressed concern for the environment (Mohr et al., 1998; Lee, 2008b). Researchers argue that consumers' confusion and skepticism toward environmental claims and marketing communication may be partly responsible for this weak degree of consumer responsiveness (Shrum et al., 1995; Lee, 2008b). Mostafa (2006) found that skepticism toward environmental claims was negatively related to Egyptian consumers' intention to buy green products. According to Shrum et al. (1995), green consumers are generally skeptical of green marketing claims and marketers should not alienate them by communicating ambiguous or misleading messages.

\section{Methodology}

The study's data were collected through a survey of Taiwanese air passengers. We used environmental behavior as the basis for segmentation because this behavior was the most pervasive in private lifestyles and household activities (Miao \& Wei, 2012) and ultimately affects the environment (Roberts, 1996; Inbakaran \& Jackson, 
2006; Paço \& Raposo, 2009). In addition to demographic characteristics, this study also examined other environmental dimensions to obtain more insights into the profiles of various segments.

The study instrument comprised three sections. The first section, which focused on individuals' environmental behaviors, included 22 items to measure the extent to which each respondent engaged in everyday activities that had positive (or less negative) effects on the environment. These items were developed based on work by Straughan \& Roberts (1999), Tilikidou (2007), and Paço \& Raposo (2010). Respondents were asked to indicate how often they engaged in each of the 22 specific environmental behaviors using a 5-point scale, each anchored with 1 (never) to 5 (always). The second section examined other environmental dimensions including environmental knowledge (10 items), environmental attitude (12 items), environmental affect (3 items), environmental responsibility ( 3 items), environmental skepticism (4 items), and intent to engage in pro-environmental air travel ( 3 items) using a 5-point scale ranging from 1 (strongly disagree) to 5 (strongly agree). The final section of the questionnaire examined the socio-demographic characteristics of the respondents.

Environmental knowledge included seven items related to high-profile global environmental issues covering air, water, land, and climate change (Kaiser et al., 1999; Ivy, Lee, \& Chuan, 1998; Abdul-Wahab, 2008) and three aviation-related environmental knowledge items developed by the researchers in this study.

Respondents were also asked to complete the 12-item New Environmental Paradigm scale (Dunlap \& Van Liere, 1978), which is the most widely accepted measure of environmental attitude. Negatively formulated items were reversed in coding the scale. Environmental affect was measured through three items adapted from Chan (2001) and Chan \& Yam (1995). The items measuring environmental skepticism were adopted and modified from Paço \& Raposo (2010). Environmental responsibility was measured using three items obtained from Lee (2008). Environmental skepticism was assessed by four items obtained from Mohr et al. (1998). Pro-environmental air travel intention assessed the respondents' intentions to make air travel decisions that harm the environment as little as possible or even benefit the environment (Steg \& Vlek, 2009). This measure contained three items adapted from Han et al. (2009). All of the measures, except for the aviation-related environmental knowledge subscale, were developed based on the relevant literature, ensuring the content validity of the scales.

Prior to commencing data collection, we pre-tested the questionnaire to assess its wording and interpretability with 30 airline travelers. Following this test and several resulting modifications, we began surveying airline customers at Taichung Airport and Taoyuan International Airport, the largest international airport in Taiwan. The Taichung Airport was chosen as the survey site because it is the gateway to Central Taiwan and its traffic has increased dramatically in recent years. A convenient sampling method was used to administer the on-site survey from mid-April to mid-May 2011. Taiwanese travelers waiting in the departure lounges were approached by the research team and asked to participate in the survey. To increase representativeness, the survey covered nearly all time intervals (i.e., morning, afternoon, etc.) across the whole week. The data were analyzed using SPSS version 10.0.

\section{Results}

After excluding incomplete and unusable responses, a total of 416 questionnaires (an effective return rate of $86 \%$ ) were retrieved for data analyses. There were more male (54\%) than female respondents and $82 \%$ of the respondents were between the ages of 20 and 50 . Nearly $70 \%$ had at least a college degree. Most respondents worked as businesspersons (40.6\%) or service industry employees $(15.9 \%)$. Nearly $74 \%$ of the respondents travelled by air one to four times per year. Among the respondents, $81 \%$ had not joined any environmental organization. Televisions, the internet, and newspapers were the main sources of environmental information for the respondents.

Fourteen of the environmental behavior variables had mean scores in excess of 3.5 and four of them had mean scores greater than four. This implied that the survey instrument was appropriate for measuring the respondents' daily involvement in environmental behavior.

The results were analyzed in a two-stage process. The first step involved a principal component factor analysis of the 22 environmental behavior items to identify the underlying factors. Only factor loadings greater than 0.5 were retained in the factor identification. Using this criterion, four items were excluded from further analysis. Only factors with eigenvalues equal to or greater than 1 were extracted. The analysis produced a five-factor solution explaining $62.7 \%$ variance, with the factors named as green consumption, recycling, political participation, economic factor, and public transport.

The first factor encompassed the most items and was named green consumption because it included items related to the purchase of eco-friendly products. The second factor, recycling, was formed from items directly related to 
recycling habits. The third factor, political participation, referred to a respondent's level of participation in, and support for, green movements. The fourth factor, economic factor, related directly to one's willingness to pay a premium for eco-friendly products. The last factor, public transport, was related to the use of public transport modes. Principal component factor analyses were also performed on other environmental variables to extract underlying dimensions using the same criterion. The Cronbach's alpha of each factor indicated an acceptable reliability or internal consistency, except for political participation and environmental responsibility (Table 1 and Table 2). Although the alpha reliabilities for these two factors were less than the threshold of 0.6 (Hair et al., 2010), the other statistical indices, such as eigenvalue and variance explained, were acceptable.

In the second step, each of the five factors was recalculated as a new variable by averaging the related items in a factor and used in the cluster analysis. A two-stage cluster analysis that included a combination of hierarchical (Ward's method) and non-hierarchical K-means cluster approaches was conducted to divide the sample into segments. After analyzing the dendrograms and agglomeration coefficients, a three-cluster solution was selected. The three clusters were named according to the range of factors present in each of them: environmentally indifferent, enlightened environmentalist, and active environmentalist. Significant differences were detected in terms of environment behavior factors among the three clusters. Table 3 presents the outcome of an ANOVA test with a Scheffe post-hoc procedure that indicates all five environmental behavior factors exhibit significant differences among the three clusters.

Thereafter, a discriminant analysis was used to determine which of the respondents' environmental behavior factors was driving the differences among the clusters and to evaluate the accuracy and stability of the cluster classification. To test whether the functions were valid predictors of cluster membership, the classification matrices of the respondents were examined. The overall percentage of the 416 respondents correctly classified by the discriminant functions was $96.7 \%$ (Table 4 ). The high rate of accuracy was indicative of the reliability of the clusters.

To investigate the profile of these segments in further detail, we examined each cluster based on socio-demographic and other environmental variables. These differences were checked for statistical significance using chi-squared and ANOVA tests. The socio-demographic characteristics of the three clusters are summarized in Table 5. Except for age, the clusters were significantly different with respect to gender, education level, occupation, monthly income, and environmental group participation. Table 6 shows how the clusters compare regarding their levels of environmental knowledge, environmental attitude, environmental responsibility, environmental affect, and environmental skepticism. Except for environmental skepticism, statistically significant differences were found among the three clusters in regards to the remaining factors.

To gain deeper insight into each cluster's pro-environmental air travel intention, the respondents were queried regarding their willingness to patronize an airline that engages in green practices, pay a higher price for more eco-friendly flights, and whether they would consider offseting $\mathrm{CO} 2$ emissions with cash or frequent flyer miles. Table 7 shows the differences in the percentage of the travelers across the clusters. According to the results, active environmentalists were more likely to engage in pro-environmental air travel than were the other two clusters.

\section{Discussion}

This study used cluster analysis and categorized Taiwanese airline customers based on their environmental behaviors into three clusters: environmentally indifferent, enlightened environmentalists, and active environmentalists. The following are the profiles associated with each cluster.

\section{(1) Cluster 1: environmentally indifferent cluster}

This cluster constituted $32 \%$ of the sample and had the highest percentage of females at $52.7 \%$. Their education and income levels were among the lowest for the clusters identified. An even distribution of occupations was observed in this cluster, which included the most blue-collar workers. They tended to acquire environmental knowledge and information through newspapers and TV programs. As Table 6 shows, the indifferent cluster had comparatively lower average scores for each environmental behavior factor, suggesting that members of this group may not pay much attention to environmental issues in their everyday lives and tend to engage in fewer environmental friendly behaviors than those in the other clusters. This cluster had the lowest score for all but one (i.e., human over nature) of the other environmental variables, indicating that people with apathetic environmental behavior are more likely to display poor performance in other environmental aspects. Furthermore, people in this cluster exhibited the lowest level of pro-environmental air travel intention.

(2) Cluster 2: enlightened environmentalist cluster 
This cluster was the largest segment, with $37 \%$ of the sample. This cluster contained slightly more males than females and had the highest percentage of young people. In terms of occupation, people in this cluster were mostly businesspeople, professionals, service industry employees, and students. They tended to acquire environmental knowledge and information through the Internet, newspapers, and TV programs. This cluster showed the highest average score on recycling behavior, followed by green consumption. Members of this group were active recyclers and attempted to purchase products with minimal environmental impact. This group displayed a higher degree of environmental awareness and strove to protect the environment. Furthermore, members of this cluster showed the strongest environmental responsibility. Their pro-environmental air travel intentions were second only to those in the active environmentalist cluster.

\section{(3) Cluster 3: active environmentalist cluster}

This cluster constituted $31 \%$ of the sample. This cluster was predominantly male $(62 \%)$ and consisted of respondents with the highest education levels (holding at least a college degree; $22.3 \%$ had graduate level education), working as businesspeople, professionals, service industry and government employees, earning higher incomes, and traveling the most frequently by air. The internet, TV programs, and magazines were their primary information sources for environmental issues. This cluster had comparatively higher average scores on each environmental behavior factor than did the other two clusters. Particularly, this group was more likely to engage in economic and political action to protect the environment. Members of this group were generally willing to make donations to environmental groups, spend more money on purchasing green products, participate in environmental protests and vote for candidates who support environmental protection. These types of behavior involve active participation in the green cause and are hence different from everyday forms of environmental protection (e.g., recycling and green consumption). This cluster also presented the highest level of pro-environmental air travel intentions. Considering their higher scores on environmental behavior factors, it seems that air travelers who perform environmentally friendly activities in other areas appear to extend these behaviors to their air travel decisions, confirming the findings of van Birgelen et al. (2011).

\section{Marketing and Managerial Implications}

The results indicated that the Internet, TV programs, newspapers, and magazines were the respondents' main sources of information on environmental issues. Airline marketers may want to make effective use of these media to communicate with their target customers. Among the three clusters, the active and the enlightened environmentalists represented the most promising target markets. The active cluster exhibited greater involvement in environmental issues and displayed the highest pro-environmental air travel intentions and, therefore, should be the primary target market for airlines' environmental marketing. Members of this cluster show genuine concern for the environment and look for ways to help the environment. They are less concerned with prices as long as the environment can be saved in some ways through their purchasing behavior. In particular, this cluster of travelers displayed the highest degree of emotional attachment toward the environment. Therefore, in addition to general environmental disclosure, a green positioning strategy of the airlines focusing on emotional benefits such as feelings of well-being, happiness, or satisfaction evoked through personal involvement with helping the environment may be pursued (Chan \& Yam, 1995; Hartmann et al., 2005). This supports the finding of Phau \& Ong (2007) that environmentally conscious consumers seek intrinsic rewards when they participate in activities that benefit the environment. Future environmental communications should convey how airlines can provide such emotional benefits to this cluster of environmentally conscious travelers.

Members of this cluster tended to be frequent flyers. Information on the airlines' environmental commitment and efforts can be provided in various in-flight magazines, journals, and brochures. Direct mail can be sent to inform them of the company's latest environmental protection initiatives to solicit their support.

Another aspect for further discussion is skepticism towards environmental claims. Although committed to environmental protection, the active cluster had a relatively high score in skepticism toward environmental claims. Accordingly, airlines may endeavor to achieve truthfulness and credibility in environmental communication rather than exaggerating their efforts to gain publicity, which may cause distrust among this cluster toward airlines' environmental messages and claims (Phau \& Ong, 2007; Shrum et al., 1995; Crane, 2000).

Looking forward, the enlightened environmentalist cluster represents a strong future prospect for airlines' green marketing efforts. This was the largest cluster and its members displayed the greatest potential for increasing environmental protection because they already perform basic environmental behaviors in their daily lives. They held positive attitudes towards the environment and showed the strongest environmental responsibility. It is recommended that airlines highlight their environmental actions to prove their long-term commitment to 
environmental protection. Airlines may consider a functional or rational strategy that delivers detailed information on environmentally beneficial product attributes or practices, such as the use of fuel-efficient engines or quieter aircraft, the provision of eco-friendly hand towels and reusable cups for use in-flight, to effectively communicate a green image to this cluster and to stimulate a more favorable perception among potential customers (Hartmann et al., 2005).

Furthermore, future environmental promotions and messages from the airlines may need to inspire a sense of environmental responsibility among the travelers in this cluster, in the hope that they will further participate with airlines' environmental measures.

Although the indifferent cluster is currently not a major target market, it should not be neglected because it accounted for $32 \%$ of the total sample. These customers do not hold as positive attitudes toward the environment as the other two clusters. They tend to be less educated about environmental issues and may not take personal responsibility for the environment. The result confirms Becken's (2007) view that information and knowledge regarding environmental issues are crucial precursors for pro-environmental actions, which was observed in that members of this cluster exhibited the lowest level of pro-environmental air travel intention. Also, this is consistent with the finding of Hares et al. (2010) that a lack of personal responsibility is a barrier to tourists' behavioral changes to reduce air travel's impact on climate change. Therefore, members of this cluster may require more exposure to environmental information and knowledge. Airlines can initiate environmental awareness campaigns to educate consumers on the severity of ecological problems and the positive gains of engaging in environmental protection activities, which would likely change consumers' perceptions in a positive way, helping develop people's sense of personal responsibility toward environmental protection (Menon et al., 1999; Laroche et al., 2001).

Finally, it must be noted that environmental communications should not be overemphasized to the detriment of the effective promotion of airline products and services. Airline advertising and communication materials should continue to place more emphasis on the perceived benefits of their products, such as price, customer service, convenience, and availability, and only make secondary appeals to them on the basis of environmental attributes (Ginsberg \& Bloom, 2004; Hartmann et al., 2005).

\section{Conclusions}

This study contributes to environmental literature by enhancing the understanding of the socio-demographic, behavioral, and attitudinal profiles of ecologically conscious (or indifferent) consumers in a non-Western air transport market. Three differentiable submarkets were successfully identified based on environmental behavior and profiled according to socio-demographic and environmental criteria, and willingness to patronize pro-environmental airlines. The results revealed that between $31 \%$ to $68 \%$ of the respondents (i.e., the enlightened and active environmentalists) were likely to be receptive to green appeals, indicating that this segment of green consumers in Taiwan exists on a large enough scale to warrant airline marketers' attention. They tend to be male, younger, better educated, higher in income and occupation status, travel more frequently, and express higher pro-environmental air travel intention. Marketers should carefully examine these clusters to determine how attractive they are and devise brand positioning strategies to appeal to these green segments through appropriate media and promotional tools. Companies that choose to ignore the green market potentially risk losing credibility and the patronage of present and future eco-conscious customers.

\section{References}

Abdul-Wahab, S. A. (2008). A preliminary investigation into the environmental awareness of the Omani public and their willingness to protect the environment. American Journal of Environmental Sciences, 4, 39-49. http://dx.doi.org/10.3844/ajessp.2008.39.49

Arcury, T. A., Scollay, S. J., \& Johnson, T. P. (1987). Sex differences in environmental concern and knowledge: the case of acid rain. Sex Roles, 16, 463-472. http://dx.doi.org/10.1007/BF00292481

Balderjahn, I., 1988. Personality variables and environmental attitudes as predictors of ecologically responsible consumption patterns. Journal of Business Research, 17, 51-56. http://dx.doi.org/10.1016/0148-2963(88)90022-7

Becken, S. (2007). Tourists' perception of international air travel's impact on the global climate and potential climate change policies. Journal of Sustainable Tourism, 15, 351-368. http://dx.doi.org/10.2167/jost710.0

Chan, K. (1999). Market segmentation of green consumers in Hong Kong. Journal of International Consumer Marketing, 12, 7-24. http://dx.doi.org/10.1300/J046v12n02_02

Chan, R. Y. K. (1999). Environmental attitudes and behavior of consumers in China: survey findings and 
implications. Journal of International Consumer Marketing, 11, 25-52. http://dx.doi.org/10.1300/J046v11n04_03

Chan, R. Y. K. (2001). Determinants of Chinese consumers' green purchase behavior. Psychology \& Marketing, 18, 389-413. http://dx.doi.org/10.1002/mar.1013

Chan, R. Y. K., \& Yam, E. (1995). Green movement in a newly industrializing area: a survey on the attitudes and behavior of Hong Kong citizens. Journal of Community \& Applied Social Psychology, 5, 273-284. http://dx.doi.org/10.1002/casp.2450050405

Chau, R. Y. K., \& Lau, L. B. Y. (2000). Antecedents of green purchases: a survey in China. Journal of Consumer Marketing, 17, 338-357. http://dx.doi.org/10.1108/07363760010335358

Chitra, K. (2007). In search of the green consumers: a perceptual study. Journal of Services Research, 7 , 173-191.

Clarke, J. P. (2006). The role of advanced air traffic management in reducing the impact of aircraft noise and enabling aviation growth. Journal of Air Transport Management, 9, 161-165. http://dx.doi.org/10.1016/S0969-6997(02)00080-7

Crane, A. (2000). Facing the backlash, green market and strategic reorientation in the 1990s. Journal of Strategic Marketing, 8, 277-296. http://dx.doi.org/10.1080/09652540050110011

Diamantopoulos, A., Schlegelmilch, B. B., Sinkovics, R. R., \& Bohlen, G. M. (2003). Can socio-demographics still play a role in profiling green consumers? A review of the evidence and an empirical investigation. Journal of Business Research, 56, 465-480. http://dx.doi.org/10.1016/S0148-2963(01)00241-7

Dunlap, R. E., \& Van Liere, K. D. (1978). The "New Environmental Paradigm": a proposed measuring instrument and preliminary results. Journal of Environmental Education, 9, 10-19. http://dx.doi.org/10.1080/00958964.1978.10801875

El-Mobaidh, A. M., Razek Taha., M. A., \& Lassheen, N. K. (2006). Classification of in-flight catering wastes in Egypt air flights and its potential as energy source (chemical approach). Waste Management, 26, 587-591. http://dx.doi.org/10.1016/j.wasman.2005.02.022

Fryxell, G. E., \& Lo, C. W. H. (2003). The influence of environmental knowledge and values on managerial behaviors on behalf of the environment: an empirical examination of managers in China. Journal of Business Ethics, 46, 45-59. http://dx.doi.org/10.1023/A:1024773012398

Ginsberg, J. M., \& Bloom, P. N. (2004). Choosing the right green marketing strategy. MIT Sloan Management Review, 46, 79-84.

Hair, J. F., Black, W. C., Babin, B. J., \& Anderson, R. E. (2010). Multivariate Data Analysis - A Global Perspective. New Jersey: Pearson.

Hares, A., Dickinson, J., \& Wilkes, K. (2010). Climate change and the air travel decisons of UK tourists. Journal of Transport Geography, 18, 466-473. http://dx.doi.org/10.1016/j.jtrangeo.2009.06.018

Hartmann, P., Ibanez, V. A., \& Sainz, F. J. F. (2005). Green branding effects on attitude: functional versus emotional positioning strategies. Marketing Intelligence \& Planning, 23, 9-29. http://dx.doi.org/10.1108/02634500510577447

Hines, J. M., Hungerford, H. R., \& Tomera, A. N. (1987). Analysis and synthesis of research on responsible environmental behavior: a meta-analysis. Journal of Environmental Education, 18, 1-8. http://dx.doi.org/10.1080/00958964.1987.9943482

IATA. (2012). International Air Transport Association. Climate Change. Retrived September 30, 2012 from http://www.iata.org/whatwedo/environment/Pages/climate_change.aspx

Inbakaran, R., \& Jackson, M. (2006). Resident attitudes inside Victoria's tourism product regions: A cluster analysis. Journal of Hospitality and Tourism Management, 13, 59-74. http://dx.doi.org/10.1375/jhtm.13.1.59

Ivy, T. G. C., Lee, C. K. E., \& Chuan, G. K. (1998). A survey of environmental knowledge, attitudes and behaviour of students in Singapore. International Research in Geographical and Environmental Education, 7, 181-202. http://dx.doi.org/10.1080/10382049808667574

Jain, S. K., \& Kaur, G. (2006). Role of socio-demographics in segmenting and profiling green consumers: an exploratory study of consumers in India. Journal of International Consumer Marketing, 18, 107-146. http://dx.doi.org/10.1300/J046v18n03_06

Kaiser, F. G., Ranney, M., Hartig, T., \& Bowler, P. A. (1999). Ecological behavior, environmental attitude, and 
feelings of responsibility for the environment. European Psychologist, 4, 59-74. http://dx.doi.org/10.1027//1016-9040.4.2.59

Kaiser, F. G., Wolfing, S., \& Fuhrer, U. (1999). Environmental attitude and ecological behaviour. Journal of Environmental Psychology, 19, 1-19. http://dx.doi.org/10.1006/jevp.1998.0107

Kerstetter, D. L., Hou, J. S., \& Lin, C. H. (2004). Profiling Taiwanese ecotourists using a behavioral approach. Tourism Management, 25, 491-498. http://dx.doi.org/10.1016/S0261-5177(03)00119-5

Kollmus, A., \& Agyeman, J. (2002). Mind the gap: why do people act enviornmentally and what are the barriers to pro-environmental behavior? Environmental Education Research, 8, 231-260. http://dx.doi.org/10.1080/13504620220145401

Kowell, S. E., \& Laska, L. B. (1992). The changing face of the environmental coalition: a research note. Enviornment and Behavior, 24, 134-144. http://dx.doi.org/10.1177/0013916592241006

Laroche, M., Bergeron, J., \& Barbaro-Forleo, G. (2001). Targeting consumers who are willing to pay more for environmentally friendly products. Journal of Consumer Marketing, 18, 503-520. http://dx.doi.org/10.1108/EUM0000000006155

Lassen, C. (2010). Environmentalist in business class: an analysis of air travel and environmental attitude. Transport Review, 30, 733-751. http://dx.doi.org/10.1080/01441641003736556

Lee, K. (2008a). Making environmental communications meaningful to female adolescents - a study in Hong Kong. Science Communication, 30, 147-176. http://dx.doi.org/10.1177/1075547008324364

Lee, K. (2008b). Opportunities for green marketing: young consumers. Marketing Intelligence \& Planning, 26, 573-586. http://dx.doi.org/10.1108/02634500810902839

Li, X. D., Poon, C. S., Lee, S. C., Chung, S. S., \& Luk, F. (2003). Waste reduction and recycling strategies for the in-flight services in the airline industry. Resources, Conservation and Recycling, 37, 87-99. http://dx.doi.org/10.1016/S0921-3449(02)00074-5

Lynes, J. K., \& Dredge, D. (2006). Going green: motivations for environmental commitment in the airline industry. A case study of Scandinavian airlines. Journal of Sustainable Tourism, 14, 116-138. http://dx.doi.org/10.1080/09669580608669048

Menon, A., Menon, A., Chowdhury, J., \& Jankovich, J. (1999). Evolving paradigm for environmental sensitivity in marketing programs: a synthesis of theory and practice. Journal of Marketing Theory and Practice, 7 , 1-15. http://dx.doi.org/10.1080/10696679.1999.11501825

Miao, L., \& Wei, W. (2013). Consumers' pro-environmental behavior and the underlying motivations: A comparsion between household and hotel settings. International Journal of Hospitality Management, 32, 102-112. http://dx.doi.org/10.1016/j.ijhm.2012.04.008

Mohr, L. A., Eroglu, D., \& Ellen, P. S. (1998). The development and testing of a measure of skepticism toward environmental claims in marketers' communications. The Journal of Consumer Affairs, 32, 30-55. http://dx.doi.org/10.1111/j.1745-6606.1998.tb00399.x

Mostafa, M. M. (2006). Antecedents of Egyptian consumers' green purchase intentions: a hierarchical multivariate regression model. Journal of International Consumer Marketing, 19, 97-126. http://dx.doi.org/10.1300/J046v19n02_06

Ottman, J. (2011). The New Rules of Green Marketing: Strategies, Tools, and Inspiration for Sustainable Branding. Berrett-Koehler, San Francisco.

Paço, A., \& Raposo, M. (2009). "Green” segmentation: an application to the Portuguese consumer market. Marketing Intelligence \& Planning, 27, 364-379. http://dx.doi.org/10.1108/02634500910955245

Paço, A., \& Raposo, M. (2010). Green consumer market segmentation: empirical findings from Portugal. International Journal of Consumer $\quad$ Studies, $\quad 34, \quad 429-436$. http://dx.doi.org/10.1111/j.1470-6431.2010.00869.x

Phau, I., \& Ong, D. (2007). An investigation of the effects of environmental claims in promotional messages for clothing brands. Marketing Intelligence \& Planning, 25, 772-788. http://dx.doi.org/10.1108/02634500710834214

Polonsky, M. J., Garma, R., \& Grau, S. L. (2011). Western consumers' understanding of carbon offsets and its relationship to behavior. Asia Pacific Journal of Marketing and Logistics, 23, 583-603. http://dx.doi.org/10.1108/13555851111183048

Rivera-Camino, J. (2007). Re-evaluating green marketing strategy: a stakeholder perspective. European Journal 
of Marketing, 41, 1328-1358. http://dx.doi.org/10.1108/03090560710821206

Roberts, J. A. (1996). Green consumers in the 1990s: profile and implications for advertising. Journal of Business Research, 36, 217-231. http://dx.doi.org/10.1016/0148-2963(95)00150-6

Samdahl, M. D., \& Robertson, R. (1989). Social determinants of environmental concern: Specification and test of the model. Environment and Behavior, 21, 57-81. http://dx.doi.org/10.1177/0013916589211004

Schlegelmilch, B. B., Bohlen, G. M., \& Diamantopoulos, A. (1996). The link between green purchasing decisions and measures of environmental consciousness. European Journal of Marketing, 30, 35-55. http://dx.doi.org/10.1108/03090569610118740

Shen, J., \& Saijo, T. (2008). Reexamining the relations between socio-demographic characteristics and individual environmental concern: Evidence from Shanghai data. Journal of Environmental Psychology, 28, 42-60. http://dx.doi.org/10.1016/j.jenvp.2007.10.003

Shrum, L. J., McCarthy, J. A., \& Lowrey, T. M. (1995). Buyer characteristics of the green consumers and their implications for advertising strategy. Journal of Advertising, 24, 71-90. http://dx.doi.org/10.1080/00913367.1995.10673477

Siriwardena, S., Hunt, G., Teisl, M. F., \& Noblet, C. L. (2012). Effective environmental marketing of green cars: a nested-logit approach. Transportation Research Part D, 17, 237-242. http://dx.doi.org/10.1016/j.trd.2011.11.004

Steg, L., \& Vlek, C. (2009). Encouraging pro-environmental behaviour: an integrative review and research agenda. Journal of Environmental Psychology, 29, 309-317. http://dx.doi.org/10.1016/j.jenvp.2008.10.004

Stern, P. C. (2000). Toward a coherent theory of environmentally significant behavior. Journal of Social Issues, 56, 407-424. http://dx.doi.org/10.1111/0022-4537.00175

Straughan, R. O., \& Roberts, J. A. (1999). Environmental segmentation alternatives: a look at green consumer behavior in the new millennium. Journal of Consumer Marketing, 16, 558-575. http://dx.doi.org/10.1108/07363769910297506

Thompson, D., W., Anderson, R. C., Hansen, E. N., \& Kahle, L. R. (2010). Green segmentation and environmental certification: insights from forest products. Business Strategy and the Environment, 19, 319-334.

Tikka, P. M., Kuitunen, M. T., \& Tynys, S. M. (2000). Effect of educational background on students' attitude, activity levels and knowledge concerning environment. The Journal of Environmental Education, 31, 12-19. http://dx.doi.org/10.1080/00958960009598640

Tilikidou. I. (2007). The effects of knowledge and attitudes upon Greek's pro-environmental purchasing behaviour. Corporeate Socail Responsibility and Environmental Management, 14, 121-134. http://dx.doi.org/10.1002/csr.123

van Birgelen, M., Semeijn, J., \& Behrens, P. (2011). Explaining pro-environment consumer behavior in air travel. Journal of Air Transport Management, 17, 125-128. http://dx.doi.org/10.1016/j.jairtraman.2010.12.013

Van Liere, K. D., \& Dunlap, R. E. (1981). Environmental concern: Does it make a difference how it's measured? Environment and Behavior, 13, 651-676. http://dx.doi.org/10.1177/0013916581136001

Vicente, P., \& Reis, E. (2007). Segmenting households according to recycling attitudes in a Portuguese urban area. Resources, Conservation and Recycling, 52, 1-12. http://dx.doi.org/10.1016/j.resconrec.2007.01.005

Zelezny, L. C., Chua, P. P., \& Aldrich, C. (2000). Elaborating on gender differences in environmentalism. Journal of Social Issues, 56, 443-457. http://dx.doi.org/10.1111/0022-4537.00177

\section{Copyrights}

Copyright for this article is retained by the author(s), with first publication rights granted to the journal.

This is an open-access article distributed under the terms and conditions of the Creative Commons Attribution license (http://creativecommons.org/licenses/by/3.0/). 